\title{
Germline gene therapy contemplated
}

A group of leading academic scientists met early this spring at the University of California, Los Angeles (UCLA) to consider what technical obstacles need to be overcome before trying germline gene therapy experiments in humans. The participants agree that researchers probably will not be ready for the first clinical trials for at least one to two decades. However, they anticipate rapid technical progress and expect it to help in overcoming current rules in the United States and elsewhere reflecting widely held political and ethical beliefs that deliberate genetic engineering of the human germline should not be attempted.

The research topic on which the day-long UCLA symposium, "Engineering the Human Germline," focused is "not distant anymore, so we need to begin to explore the issue, deepen the dialogue, and make it acceptable," says symposium organizer Gregory Stock, who is director of the UCLA program on science, technology, and society.

Stock and symposium coorganizer John Campbell a neuroscientist at the UCLA School of Medicine, argue that progress along several fronts, such as building human artificial chromosomes, analyzing genomic sequences, and learning how to control gene activity may soon make it easier to engineer human genes at the germline than at the somatic cell level.

Campbell sees germline gene therapy as offering some advantages over current efforts that focus on delivering engineered genes to somatic cells. "I think of the germline as an ideal form of gene therapy, where the same vehicle could be used for delivering every gene that is made, and control becomes the big issue," Campbell says. "A big problem with somatic cell gene therapy is getting genes to the cells where they're needed," he adds.

Meticulous "showcase" studies in model animal systems will be needed before clinical trials are attempted, according to Campbell. "In 20 years, we'll have what we need in terms of controls so what we do will be reasonably safe and pinpointed before we start fiddling with embryos." He and Stock also say that some safety and ethical concerns can be circumvented by adding controls, such as selfdestruct elements, to keep germline genetic additions from being permanently inherited.

The UCLA symposium participants seem to reflect a renewed sense of confidence in gene therapy's technical progress, marking a striking shift since 1995. Then, an expert committee, appointed by NIH (Bethesda, MD) director Harold Varmus and cochaired by Stuart Orkin of Harvard Medical School
(Boston) and Arno Motulsky of the University of Washington (Seattle), delivered a report criticizing scientists at companies and universities who work in this field, in part for creating false expectations about the progress they had made (Bio/Technology 14:14, 1996). That report urged a "greater focus on basic research," and reminded investigators that, even though prospects for this research "are great, clinical efficacy has not been definitively

\section{So far, no researchers have come forward with a scheme to test gene transfers in humans at the germline level.}

demonstrated," and that "significant problems remain in all basic aspects of gene therapy."

More than 200 gene transfer-based, therapeutic clinical trials have been undertaken, according to the database maintained by the NIH Office of Recombinant DNA Activities (ORDA). Although no unusual safety concerns have been reported, results indicating unequivocal therapeutic successes have also not yet been reported for any of these somatic cell-directed, gene-transfer clinical tests.

So far, no researchers have come forward with a scheme to test gene transfers in humans at the germline level. Indeed, because the topic of germline gene therapy has been taboo, technical progress now being made in the research areas that underpin it could lead to "great dangers if [clinical proposals] are sprung unexpectedly" on the public, Stock says. He does not want to see germline therapy treated the same as human cloning was throughout much of 1997, "where people jumped to legislate research restrictions" even though no one was proposing tests of such procedures on human cells.
However, germline procedures already are subject to restrictions. Canada and many countries in Europe are "quite opposed to germline interventions, but in the United States, the discussion has been moving to whether it would be all right to do this in principle," says Leroy Walters, director of the Center for Bioethics at Georgetown University (Washington, DC) and former chair of the NIH Recombinant DNA Advisory Committee. He adds, "The key question is, if the technical means are well developed, whether the intervention is intended to prevent disease."

Meanwhile, US regulatory officials insist on rigorous testing to ensure that transferred genetic materials are not inadvertently introduced into germline tissues during somatic gene therapy clinical and preclinical tests. For instance, last year officials at the US Food and Drug Administration (FDA; Rockville, MD) told gene therapy researchers at the University of Pennsylvania (Philadelphia) to prove that the vectors they plan to use in clinical protocols do not deliver and integrate genes into mouse gonadal tissues, says former ORDA Director Nelson Wivel, who is now part of the University of Pennsylvania gene therapy research team.

"We loaded high amounts of the vector to get it into reproductive tissues of mice," Wivel says. PCR tests indicate that some of the overloaded vector material duly appears in mouse germline tissues, but other tests prove that the transferred genetic material does not become integrated there and is not passed to offspring mice, he says.

Although ORDA officials have asked gene therapy researchers to review clinical protocols for evidence of any germline transfers among human subjects, there is "not much definitive data," Wivel says. Available anecdotal findings provide "no evidence for integrated DNA in germline tissues" among those human subjects.

Jeffrey L. Fox

\section{Researchers wary of fear-based ban on lentivirus gene therapy}

Some researchers who are developing lentivirus-based gene therapies fear that, despite assurances from officials at the US Food and Drug Administration (FDA, Rockville, MD), policy decisions about clin- ical uses of lentivirus-based vectors may depend more on emotional responses from the public than on assessments of the safety data. Although no candidate lentivirusbased vectors have yet been submitted for 